\title{
DIASTEREO ISOMERIC erythro AND threo FORMS OF 2,3-EPOXY-1-PHENYLPHOSPHOLANE 1-OXIDES SYNTHESIZED BY AN ACTION OF HYDROGEN PEROXIDE WITH BASE ON 1-PHENYL-2-PHOSPHOLENE 1-OXIDE
}

\author{
Hirono Totsuka, Motoki Maeda, Valluru Krishna Reddy, Masaki Takahashi, and Mitsuji Yamamshita* \\ Department of Materials Chemisty, Faculty of Engineering, Shizuoka University, Hamamatsu 432-8561, Japan, \\ Phone \& Fax: +81-53-478-1144, E-mail: tcmyama@ipc.shizuoka.ac.jp
}

\begin{abstract}
Diastereo isomeric erythro and threo forms of 2,3-epoxy-1-phenylphospholane 1-oxides were synthesized from 1-phenyl-2-phospholene 1-oxide using $30 \%$ hydrogen peroxide with $\mathrm{NaOH}$. The selectivity of the diastereo isomers was depended on reaction time and concentration of peroxide and base, and kind of solvents, which controlled the selectivity of the eyrthro and threo forms.
\end{abstract}

\section{Introduction}

Phospha sugar is one of sugar analogs that have a phosphorous atom in place of the ring oxygen atom of normal sugars. Recently, several nucleoside derivatives of sugars, e.g., AZT (1) and Ribavirn (2), are prepared and used as antivirus agents $(1,2)$. In addition to the nucleoside of normal sugars, sugar modified novel nucleoside derivatives of pseudo sugars or hetero sugars such as aza- (3), carba- (4), and thia-sugars (5) have been synthesized and reported. In the present work, we deal with the successful preparative method for formation of the epoxide of 2-phospholene 1-oxide derivatives. 2,3-Epoxy-1-phenylphospholane 1-oxide is an anhydro type phospha sugar derivative and a potential precursor for phospha sugar derivatives. In our laboratory, an efficient method for the stereospecific epoxidation of 2-phospholenes using sodium peroxide as a reagent was developed to make the corresponding epoxide such as 2,3-epoxy-1-phenylphospholane 1-oxide (6). Instead of using sodium peroxide, using $30 \%$ hydrogen peroxide and base are less expensive, less harmful to the environment, less dangerous for handling, and more practical than the previous method. The new method of synthesizing diastereo isomeric erythro and threo forms of 2,3-epoxy-1-phenylphospholane 1-oxides was optimized using hydrogen peroxide with base by different experimental conditions.

\section{Results and Discussion}

Scheme 1 shows the epoxidation of 1-phenyl-2-phosopholene 1-oxide (1) to prepare 2,3-epoxy-1-phenylphospholane 1-oxide (2). The rcaction afforded the diastcrcomcric epoxide mixturc of erythro $\mathbf{2 a}$, which was the major product, and threo $\mathbf{2 b}$. 
Spectral data of $2 \mathbf{a}$ and $\mathbf{2 b}$ were taken by ${ }^{1} \mathrm{H}-\mathrm{NMR}$ and ${ }^{13} \mathrm{C}$-NMR. The preparation method and NMR data are reported in later experimental section.

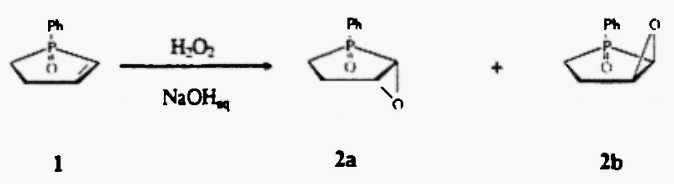

Scheme 1

Table 1. Synthesis of diastereo isomeric erythro and threo forms of

2,3-epoxy-1-phenylphospholane 1-oxide under different conditions.

\begin{tabular}{|c|c|c|c|c|c|c|}
\hline \multirow[b]{2}{*}{ Entry } & \multicolumn{4}{|c|}{ Reaction Conditions } & \multicolumn{2}{|c|}{ Products } \\
\hline & Solvent & $\begin{array}{l}\mathrm{H}_{2} \mathrm{O}_{2} \\
{[0 Q]}\end{array}$ & $\begin{array}{l}\mathrm{NaOH} \\
{[\mathrm{eq}]}\end{array}$ & Temp. Time & $\begin{array}{l}\text { Yield } \\
{[\%]}\end{array}$ & $\begin{array}{l}\text { Ratio of } \\
\text { eryhro:threo }\end{array}$ \\
\hline 1 & Ethanol & 40 & 10 & r.t. $1 \mathrm{~d}$ & 8 & $5: 3$ \\
\hline 2 & Ethanol & 40 & 10 & r.t. $5 \mathrm{~h}$ & 5 & $2: 1$ \\
\hline 3 & Ethanol & 40 & 10 & r.t. 3d & 10 & $5: 3$ \\
\hline 4 & Ethanol & 40 & 10 & r.t. $6 \mathrm{~d}$ & 40 & $10: 7$ \\
\hline 5 & Ethanol & 40 & 10 & $40^{\circ} \mathrm{C} 1 \mathrm{~d}$ & 45 & $2: 1$ \\
\hline 6 & Ethanol & 40 & 0.1 & $40^{\circ} \mathrm{C} 1 \mathrm{~d}$ & 0 & $\mathrm{ND}^{2)}$ \\
\hline 7 & Ethanol & 40 & 1 & $40^{\circ} \mathrm{C} 1 \mathrm{~d}$ & 0 & ND" \\
\hline 8 & Ethanot & 40 & 20 & p.t. 10 & 1 & ND \\
\hline 9 & Ethanol & 120 & 10 & P.L. 1d & 6 & $2: 1$ \\
\hline
\end{tabular}

Table 1 shows synthesis of diastereo isomeric erythro and threo forms of 2,3-epoxy-1-phenylphospholane 1-oxides under different conditions. The selectivity of erythro to threo was compared and analyzed for each condition. Increased temperature gave a short reaction time and a high selectivity in erythro form. The increased concentration on $\mathrm{H}_{2} \mathrm{O}$, gave the increased selectivity. The yield was decreased with increasing $\mathrm{NaOH}$ concentration. The reaction time was changed from 5 hr to 6 days. The yield was increased with increasing the reaction time, but the selectivity of the erythro form was decreased.

Only by using the pure erythro form, a further reaction was tested under the same reaction condition for 6 days as shown in Table 1 (entry 4). The results obtained before and after the treatment were shown in Table 2. There was only the erythro before the reaction, but the isomerization (by epimerization of erythro) was occurred during 6 days. As the result, the selectivity was decreased with increasing of the reaction time, and the reduced erythro selectivity was rationalized by epimerization under the reaction conditions.

Table 2. Erythro to threo ratio of 2,3-epoxy-1-phenylphospholane 1-oxide in the isomerization.

\begin{tabular}{|c|c|c|c|c|c|c|}
\hline \multirow[b]{2}{*}{ Reaction" } & \multicolumn{4}{|c|}{ Reaction Conditions } & \multicolumn{2}{|c|}{ Products } \\
\hline & Solvent & $\begin{array}{l}\mathrm{H}_{2} \mathrm{O}_{2} \\
\text { [eq] }\end{array}$ & $\begin{array}{l}\mathrm{NaOH} \\
{[\mathrm{eq}]}\end{array}$ & Temp. Time & $\begin{array}{c}\text { Yield } \\
\text { [\%] }\end{array}$ & $\begin{array}{c}\text { Ratio of } \\
\text { erythro:threo }\end{array}$ \\
\hline before & $\ldots$ & - & $\longrightarrow$ & r.t. Od & 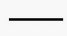 & $1: 0$ \\
\hline after & Ethanol & 40 & 10 & r.t. $6 \mathrm{~d}$ & 100 & $10: 7$ \\
\hline
\end{tabular}

a) Belore and ater mean the the staring and anding times, respectively, of the treatment. 
The condition to suppress the isomerization was determined by changing the reaction medium. Firstly, the relationship of the formed epoxide ratio (erythro and threo) with epoxidation condition in different alcohol solvents with different polarity was observed. Table 3 shows the results of the product yield and erythro to threo ratio in the solvent: methanol, ethanol, and isopropanol. The selectivity of erythro form in ethanol was higher than the other two. In the order (entry 1, 2, and 3), the molecular size of solvents was increased, and the solvent polarity (7) was decreased; this may attribute the product ratio to facile formation of pentavalent phosphorane $\mathrm{P}(\mathrm{V})$-erythro intermediate and also to stabilizing the $\mathrm{P}(\mathrm{V})$-threo intermediate to increase threo form in highly polarized methanol, which is shown in Scheme 2 (8). As the result, the kind of alcohols have influenced on the result in Table 3.

Table 3. Synthesis of diastereo isomeric erythro and threo forms of

2,3-epoxy-1-phenylphospholane 1-oxide with changing the alcohol solvent.

\begin{tabular}{|c|c|c|c|c|c|c|c|}
\hline \multirow[b]{2}{*}{ Entry } & \multicolumn{5}{|c|}{ Reaction Conditions } & \multicolumn{2}{|r|}{ Products } \\
\hline & Solvent & Formula & $\varepsilon^{b)}$ & $\begin{array}{c}\mathrm{NaOH} \\
{[e q]}\end{array}$ & Temp. Time & $\begin{array}{c}\text { Yield } \\
{[\%]}\end{array}$ & $\begin{array}{c}\text { Ratio of } \\
\text { erythro.threo }\end{array}$ \\
\hline 1 & Methanol & $\mathrm{CH}_{4} \mathrm{O}$ & 32.6 & 10 & r.t. $6 \mathrm{~d}$ & 50 & $10: 9$ \\
\hline 2 & Ethanol & $\mathrm{C}_{2} \mathrm{H}_{\mathrm{B}} \mathrm{O}$ & 24.3 & 10 & r.t. $6 \mathrm{~d}$ & 41 & $2: 1$ \\
\hline 3 & Isopropanol & $\mathrm{C}_{3} \mathrm{H}_{\mathrm{B}} \mathrm{O}$ & 18.3 & 10 & r.t. $6 \mathrm{~d}$ & 23 & $5: 3$ \\
\hline
\end{tabular}

a) Solvent formula, b) Dielectric constant; see ret. (8)

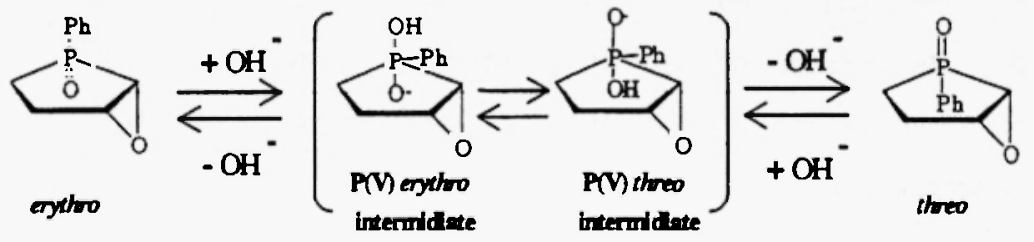

Scheme 2

Secondly, the relationship with different solvent systems; not only homogeneous but also heterogeneous solution system, were observed: diethylether, tert-butanol, THF, and chloroform. Any of these four solvents, diethylether and tert-butanol gave higher yield and selectivity than the other solvents. In the case of chloroform, threo instead of erythro became the dominant isomer. The solvent effect is also explained by the less polarity of the solvent causing the predominant formation of erythro form and heterogeneous reaction system suppressing the isomerization to threo form except chloroform. 
Table 4. Synthesis of diastereo isomeric erythro and threo forms of

2,3-epoxy-1-phenylphospholane 1-oxide with changing the solvent system.

\begin{tabular}{|c|c|c|c|c|c|c|c|c|}
\hline \multirow[b]{2}{*}{ Entry } & \multicolumn{6}{|c|}{ Reaction conditions } & \multicolumn{2}{|r|}{ Products } \\
\hline & Solvent & Formula $^{a}$ & $\varepsilon^{b)}$ & $\begin{array}{l}\text { Solubility } \\
\left.\text { in } \mathrm{H}_{2} \mathrm{O}[\%]_{0}\right]^{c)}\end{array}$ & $\begin{array}{c}\mathrm{NaOH} \\
\text { [eq] }\end{array}$ & Temp. Time & $\begin{array}{r}\text { Yield } \\
{[\%]} \\
\end{array}$ & $\begin{array}{c}\text { Ratio of } \\
\text { erythro:threo }\end{array}$ \\
\hline 1 & Diethyl ether & $\mathrm{C}_{4} \mathrm{H}_{10} \mathrm{O}$ & 4.22 & 7.5 & 10 & r.t. $6 \mathrm{~d}$ & 47 & $2: 1$ \\
\hline $2 t$ & tert-Butanol & $\mathrm{C}_{4} \mathrm{H}_{10} \mathrm{O}$ & 12.2 & Miscible & 10 & r.t. $6 \mathrm{~d}$ & 61 & $2: 1$ \\
\hline 3 & THF & $\mathrm{C}_{4} \mathrm{H}_{8} \mathrm{O}$ & 7.4 & Solubile & 10 & r.t. $6 d$ & 22 & $10: 9$ \\
\hline 4 & Chloroform & $\mathrm{CHCl}_{3}$ & 4.7 & 0.82 & 10 & r.t. $6 d$ & 26 & $7: 10^{\circ}$ \\
\hline
\end{tabular}

Thirdly, the effect of different bases on the synthesis of diastereo isomeric enythro and threo forms was observed and shown in Table 5. The combination of $\mathrm{KOH}$ and tert-butanol gave the highest selectivity.

Table 5. Synthesis of diastereo isomeric erythro and threo forms of 2,3-epoxy-1-phenylphospholane 1-oxide with changing base.

\begin{tabular}{|c|c|c|c|c|c|c|}
\hline \multirow[b]{2}{*}{ Entry } & \multicolumn{4}{|c|}{ Reaction conditions } & \multicolumn{2}{|c|}{ Products } \\
\hline & Solvent & Base & [eq] & Condition & Yield [\%] & $\begin{array}{c}\text { Ratio of } \\
\text { erythro:threo }\end{array}$ \\
\hline 1 & Ethanol & $\mathrm{NaHCO}_{3}$ & 10 & r.t. $6 d$ & 0 & $N D^{a)}$ \\
\hline 2 & Ethanol & $\mathrm{KOH}$ & 10 & r.t. $6 d$ & 70 & $5: 3$ \\
\hline 3 & tert-Butanol & $\mathrm{KOH}$ & 10 & r.t. $6 \mathrm{~d}$ & 72 & $2: 1$ \\
\hline 4 & tert-Butanol & $\mathrm{NaOH}$ & 10 & r.t. $6 d$ & 52 & $5: 3$ \\
\hline 5 & tert-Butanol & $\mathrm{NaCO}_{3}$ & 10 & r.t. $6 d$ & 0 & $N D^{a)}$ \\
\hline 6 & tert-Butanol & $\mathrm{Ca}(\mathrm{OH})_{2}$ & 10 & r.t. $6 \mathrm{~d}$ & 0 & $N D^{a)}$ \\
\hline
\end{tabular}

a) Not determind

The efficient heterogeneous epoxidation of $\alpha, \beta$-unsaturated ketones with hydrogen peroxide using hydrotalcite catalysts under the mild reaction conditions was recommended (9). We tried several hydrotalcite catalysts (1 to 2 equivalents) (10) under the mild reaction condition for the case of preparation of 2,3-epoxy-1-phenylphospholane 1-oxides. However, we did not get any yield of the epoxide product. The catalyst was oxidized by hydrogen peroxide ion, and the formed oxide of the catalyst had no ability to oxidize 2-phospholene 1 because of less oxidizable property caused by less electron density of the $\mathrm{C}=\mathrm{C}$ double bond with $\alpha$-phosphoryl group. Therefore, the epoxidation reaction was prevented by the catalyst.

\section{Conclusion}

In summary, the present epoxidation procedure was successful in controlling the diasteromer ratio of erythro and threo 
forms of 2,3-epoxy-1-phenylphospholane 1-oxide by convenient and easily handling $30 \%$ hydrogen peroxide reagent. To increase the stereospecific epoxidation of 2-phospholenes, we have determined the optimized conditions by changing the epoxidation conditions, i.e., the reaction time, concentration of peroxide and base, and solvent type. The over-all protocol is practical and quite efficient. Further studies on epoxidation, e.g., detailed study on the substituent effect and investigation of the generality of this novel method of epoxidation of 2-phospholenes, as well as nucleophilic substitution reaction of the epoxide to prepare phospha sugar glycosides are currently under investigation in our laboratory (11). By these procedures, erythro or threo rich epoxide can be produced by changing the experimental conditions.

\section{Experimental}

Preparation of 2,3-epoxy-1-phenylphospholane 1-oxide (2) from 1-phenyl-2-phosopholene 1-oxide (1): As our synthetic methods, to 1-phenyl-2-phosopholene 1-oxide $(1.0 \mathrm{~g}, 5.6 \mathrm{mmol})(1)$ in the mixture of $30 \mathrm{~mL}$ of ethanol and $8 \mathrm{~mL}$ of $30 \%$ hydrogen peroxide was added $\mathrm{NaOH}$ aq $(15 \%, 58.5 \mathrm{mmol})$. The reaction mixture was stirred for 6 days at room temperature. The reaction product was extracted with chloroform from the reaction mixture. Diastereo isomeric erythro 2a and threo $2 \mathrm{~b}$ forms of 2,3-epoxy-1-phenylphospholane 1-oxide (2) (in scheme 1) were separated by silica gel column chromatography (EtOAc: $\mathrm{CH}_{3} \mathrm{OH}=20: 1$ ). Tables 6 and 7 show the NMR data of the erythro 2a and threo $2 \mathrm{~b}$ forms.

Table 6. ' ${ }^{1} \mathrm{H}-\mathrm{NMR}$ data of erythro 2a form of 2,3-epoxy-1-phenylphospholane 1-oxide.

\begin{tabular}{cl}
\hline${ }^{1} \mathrm{H} N M R\left(\mathrm{CDCl}_{3}\right)$ & \multicolumn{1}{c}{${ }^{13} \mathrm{C} \mathrm{NMR}\left(\mathrm{CDCl}_{3}\right)$} \\
$\delta(\mathrm{ppm})$ & \multicolumn{1}{c}{$\delta(\mathrm{ppm})$} \\
\hline $1.94-2.1(\mathrm{~m}, 2 \mathrm{H}, \mathrm{H}-4)$ & $19.49(\mathrm{~d}, \mathrm{~J}=71.35, \mathrm{C}-5)$ \\
$1.94-2.68(\mathrm{~m}, 2 \mathrm{H}, \mathrm{H}-5)$ & $24.11(\mathrm{~s}, \mathrm{C}-4)$ \\
$3.45(\mathrm{dd}, 1 \mathrm{H}, \mathrm{J} 2, \mathrm{P}=29.1 \mathrm{~Hz}$, & $50.66(\mathrm{~d}, \mathrm{~J}=98.9 \mathrm{~Hz}, \mathrm{C}-2)$ \\
$\mathrm{J} 2,3=3.0 \mathrm{~Hz}, \mathrm{H}-2)$ & $55.38(\mathrm{~d}, \mathrm{~J}=16.1 \mathrm{~Hz}, \mathrm{C}-3)$ \\
$3.82-3.86(\mathrm{~m}, \mathrm{H}, \mathrm{H}-3)$ & $129.03(\mathrm{~d}, \mathrm{~J}=11.8 \mathrm{~Hz}, \mathrm{Ph})$ \\
$7.15-7.76(\mathrm{~m}, 5 \mathrm{H}, \mathrm{Ph})$ & $130.00(\mathrm{~d}, \mathrm{~J}=9.4 \mathrm{~Hz}, \mathrm{Ph})$ \\
$7.15-7.76(\mathrm{~m}, 5 \mathrm{H}, \mathrm{Ph})$ & $132.61(\mathrm{~d}, \mathrm{~J}=3.1 \mathrm{~Hz}, \mathrm{Ph})$ \\
\hline
\end{tabular}

Table 7. ${ }^{1} \mathrm{H}-\mathrm{NMR}$ data of threo $\mathbf{2 b}$ form of 2,3-epoxy-1-phenylphospholane 1-oxide.

\begin{tabular}{cl}
\hline${ }^{1} \mathrm{H} N M R\left(\mathrm{CDC}_{3}\right)$ & \multicolumn{1}{c}{${ }^{13} \mathrm{C} \mathrm{NMR}(\mathrm{CDC} b)$} \\
$\delta(\mathrm{ppm})$ & \multicolumn{1}{c}{$\delta(\mathrm{ppm})$} \\
\hline $1.94-2.17(\mathrm{~m}, 2 \mathrm{H}, \mathrm{H}-4)$ & $22.48(\mathrm{~d}, 70.2 \mathrm{~Hz}, \mathrm{C}-5)$ \\
$1.94-2.68(\mathrm{~m}, 2 \mathrm{H}, \mathrm{H}-5)$ & $24.29(\mathrm{~d}, 2.5 \mathrm{~Hz}, \mathrm{C}-4)$ \\
$3.51(\mathrm{dd}, 1 \mathrm{H}, \mathrm{J} 2, \mathrm{P}=28.7 \mathrm{~Hz}$, & $50.60(\mathrm{~d}, 102.0 \mathrm{~Hz}, \mathrm{C}-2)$ \\
$\mathrm{J} 2,3=3.0 \mathrm{~Hz}, \mathrm{H}-2)$ & $57.39(\mathrm{~d}, \mathrm{~J}=11.2 \mathrm{~Hz}, \mathrm{C}-3)$ \\
$3.93-3.96(\mathrm{~m}, \mathrm{H}, \mathrm{H}-3)$ & $128.72(\mathrm{~d}, \mathrm{JCCP}=12.4 \mathrm{~Hz}, \mathrm{Ph})$ \\
$8.00-7.51(\mathrm{~m}, 5 \mathrm{H}, \mathrm{Ph})$ & $131.16(\mathrm{~d}, \mathrm{JCCCP}=10.0 \mathrm{~Hz}, \mathrm{Ph})$ \\
& $132.60(\mathrm{~d}, \mathrm{Jccccp}=3.1 \mathrm{~Hz}, \mathrm{Ph})$ \\
\hline
\end{tabular}




\section{Rferences and Notes}

(1) Mitsuya, H.; Weinhold, KJ.; St. Clair, M.H.; Lehrmann, S.N.; Gallo, R. S.; Bolognes, O.; Barry, D. W., S. Proc. Nat. Acad. Sci USA 1985, 82, 7096-7100.

(2) McCormac, J.B.; Getchell, J.P.; Mitchel, S.W.; Hicks, D.R., Lancet ii 1984, 1367-1369.

(3) Momotake, A; Tago, H.; Yokoyama, M., J. Chem. Soc., Perkin Trans. 1 1999, 1193-1200.

(4) Wang, P.; Agrofoglio, L.A.; Newton, M.G; Chu, C. K. J. Org. Chem. 1999, 64, 4173-4178.

(5) Branalt, J.; Kvarunstrom, I; Kiklasson, G; Svensson, S. C. T., J. Org. Chem. 1994, 59, 1783-1788.

(6) Yamashita, M.; Reddy, V. K.; Rao, L. N.; Hanta, B.; Maeda, M.; Suzuki, K.; Totsuka, H.; Takahashi, M.; Oshikawa, T., Tetraheron Lett. 2003, 44 2339-2341.

(7) Senoo, M.; Arai, T., Yuki Kagaku Hanno ni Okeru Yobai Koka (Solvent Effects in Organic Chemistry Reactions); Sangyo Tosho: Tokyo, 1970, 68-69.

(8) For pseudo rotaion, see; Quin, L. D.; Quin, G S., A Guide to Organophosphorus Chemistry; Wiley-Interscience: New York, 2000, 17-19.

(9) Yamaguchi, K; Mori, K; Mizugaki, T.; Ebitani, K; Kaneda, K., J. Org. Chem. 2000, 65, 6897-6903.

(10) According to reference (9), ammonium iron(II) sulfate hexahydrate, manganese(II) sulfate pentahydrate, manganese(II) acetate, stannous(II) chloride, sodium tungstate(VI), cobalt(II) chloride, and cerous(III) chloride were used as the catalysts.

(11) For examples, tetrofuranose $\mathrm{N}$-glycosides of phospha sugars or 2-amino-3-hydroxy-1-phenylphospholane 1-oxides.

\section{Received on March 27, 2004.}

